\title{
Identifikasi Allopurinol dan Deksametason Dalam Jamu Secara Simultan Dengan Metode Kromatografi Lapis Tipis (KLT)
}

\section{Simultaneous Identification of Allopurinol and Dexamethasone in Herbal Medicine by Thin} Layer Chromatography (TLC) Method

Abdul Roni $^{(1)}$, Tri Minarsih ${ }^{(2)}$

${ }^{(1(2))}$ Program Studi Farmasi, Universitas Ngudi Waluyo Ungaran

Email : abdulroni@unw.ac.id

\begin{abstract}
ABSTRAK
Latar Belakang: Jamu masih banyak digunakan oleh masyarakat Indonesia untuk pengobatan. BPOM melarang penggunaan Bahan Kimia Obat di dalam sediaan jamu. Penelitian ini bertujuan untuk mengembangkan metode Kromatografi Lapis Tipis ( KLT) yang dapat secara simultan menganalisis adanya kandungan Allopurinol dan Deksamethason dalam jamu, serta untuk mengidentifikasi adanya kandungan allopurinol dan deksametason dalam sampel jamu. Metode yang digunakan adalah KLT, sampel yang digunakan terdiri dari 8 sampel jamu pegal linu dan asam urat yang beredar di Ungaran, yang tidak terdaftar pada BPOM. Fase Diam yang digunakan adalah Lempeng Silika Gel GF 254. Hasil dari penelitian ini pada optimasi metode KLT diperoleh fase gerak yang terdiri dari etil asetat dan kloroform dengan perbadingan 4:1. Pada komposisi fase gerak tersebut, bercak allopurinol dan deksametason dapat terpisah dan diperoleh harga Rf baku allopurinol sebesar 0.21 , sedangkan harga Rf baku deksametason sebesar 0.78 , memenuhi persyaratan nilai yang baik yaitu $0.2-0.8$ Dari 8 sampel yang dianalisis terdapat 2 sampel yang mengandung Allopurinol, yaitu sampel $\mathrm{E}$ dan $\mathrm{F}$ dan tidak ada sampel yang mengandung deksametason.

Kesimpulan : Metode KLT yang dikembangkan mampu memisahkan bercak noda Allopurinol dan Deksametason, dan terdapat 2 sampel yang mengandung allopurinol dan tidak ada yang mengandung deksametason
\end{abstract}

Kata kunci : Jamu, Allopurinol, Deksametason, KLT

\section{ABSTRACT}

Background: Jamu is still widely used by the Indonesian population for treatment. The BPOM prohibits the use of medicinal chemicals in herbal preparations. This study aims to develop a thin layer chromatography (TLC) method capable of simultaneously analyzing the presence of allopurinol and dexamethasone in herbal medicine, as well as identifying the presence of allopurinol and dexamethasone in herbal medicine samples.

The method used is TLC, the sample used is 8 jamu samples against aches and pains and gout circulating in Ungaran, which are not registered with BPOM. The stationary phase used is a plate of silica gel GF 254.

The results of this study on the optimization of the TLC method allowed to obtain a mobile phase consisting of ethyl acetate and chloroform with a ratio of $4: 1$. In the composition of the mobile phase, the spots of allopurinol and dexamethasone can be separated, and the standard $R f$ value of allopurinol is 0.21 , while the standard $R f$ value of dexamethasone is 0.78 , responding to the requirements of a good value of 0.2 to 0.8. samples analyzed, there were 2 samples containing allopurinol, namely samples $E$ and $F$ and none of the samples contained dexamethasone.

Conclusion: The developed TLC method made it possible to separate the Allopurinol and Dexamethasone stains, and there were 2 samples containing allopurinol and none containing dexamethasone.

Keywords: Jamu, Allopurinol, Dexamethasone, TLC 


\section{PENDAHULUAN}

Dalam Peraturan Kementrian Kesehatan No 007 Tahun 2012 disebutkan bahwa Obat Tradisional tidak diperbolehkan mengandung Bahan Kimia Obat (BKO) (Kemenkes RI, 2012). Berdasarkan temuan Badan Pengawasan Obat dan Makanan (BPOM) pada tahun 2013, bahwa BPOM menarik 59 jenis jamu mengandung bahan kimia obat. Pada tahun 2014 BPOM juga menarik 51 jenis jamu mengandung bahan kimia obat dan tidak memiliki izin edar (Maisura et al., 2018).

Dexamethason dan allopurinol merupakan obat yang sering ditambahkan dalam jamu, khasiat dari dexamethason adalah analgetik dan antiradang kuat. Dexamethason sering mengakibatkan myopathy (otot menyusut dan nyeri) pada penggunaan oral, juga menekan adrenal agak kuat (Saputra, 2015). Allopurinol merupakan obat yang digunakan untuk pengobatan asam urat kronis, penggunaan allopurinol memiliki beberapa efek samping yaitu kemerahan pada kulit, leukopenia, kadang-kadang terjadi toksisitas pada gastrointestinal dan meningkatkan serangan akut gout pada awal terapi (Pertamawati, 2015).

Metode yang digunakan untuk analisis adalah Kromatografi Lapis Tipis (KLT). Kromatografi merupakan teknik pemisahan campuran berdasarkan perbedaan distribusi dari komponen-komponen campuran diantara dua fase yaitu fase diam dan fase gerak. Keuntungan utama dari kromatografi lapis tipis dibandingkan dengan kromatografi cair kinerja tinggi adalah analisis beberapa sampel dapat dilakukan secara simultan dengan menggunakan fase gerak dalam jumlah kecil (Wulandari, 2011).

Tujuan penelitian ini untuk mengembangkan metode KLT dalam menganalisis allopurinol dan deksametason serta menganalsis apakah jamu pegel linu yang beredar mengandung allopurinol atau deksametason.

\section{METODE PENELITIAN}

\section{Alat dan Bahan}

Alat yang digunakan: lampu UV 254 dan 356, alat gelas, sonikator, timbangan analitik, chamber, waterbath.

Bahan yang digunakan: Baku allopurinol, baku deksametason, Kloroform (Merck), etil asetat (Merck), methanol (Merck), n butanol (Merck), Amonia (Merck), lempeng KLT GF 254, 8 sampel jamu pegal linu.

\section{Metode Penelitian}

\section{a. Pengambilan sampel}

Sampel terdiri dari 8 sampel jamu pegal linu yang tidak teregistrasi oleh BPOM. Untuk sampel yang dalam bentuk kapsul, diambil 10 kapsul, dikeluarkan serbuk jamunya, dihaluskan dan dihomogenkan

b. Uji Organoleptis sampel jamu

Dilakukan pengamatan terhadap bentuk, warna dan rasa dari sampel jamu. Pada sampel jamu yang berbentuk kapsul, maka sampel dikeluarkan dulu dari cangkang kapsulnya untuk selanjutnya dilakukan uji organoleptis

\section{c. Pembuatan baku Allopurinol dan deksametason}

Ditimbang $25 \mathrm{mg}$ baku allopurinol dan deksametason, dilarutkan dengan metanol sampai sebanyak $25,0 \mathrm{ml}$

\section{d. Penyiapan dan optimasi Fase Gerak}

Fase gerak terdiri dari 4 jenis komposisi, yaitu kloroform : metanol (9:1), N Butanol : Amonium Hidroksida 
(1:1) dan kloroform : etil asetat ( 1:2 dan 1:4). Selanjutnya masing-masing fase gerak digunakan untuk mengelusi lempeng KLT yang sudah ditotolkan baku allopurinol dan deksametason

\section{e. Preparasi sampel}

$250 \mathrm{mg}$ serbuk sampel jamu ataupun sampel simulasi ditambahkan $25 \mathrm{ml}$ metanol, homogenkan dengan sonikator, kemudian disaring dengan kertas saring Whatman No 41 (Asra et al., 2018).

\section{f. KLT pada simulasi sampel dan sampel jamu}

Disiapkan lempeng KLT dengan jarak rambatan $10 \mathrm{~cm}$, batas atas $1 \mathrm{~cm}$, batas bawah $1 \mathrm{~cm}$. Fase gerak yang terpilih dari hasil optimasi dimasukkan chamber, sebelum digunakan untuk mengelusi sampel, fase gerak dijenuhkan terlebih dahulu. Filtrat simulasi sampel ditotolkan bersama baku allopurinol dan deksametason, demikian juga filtrat sampel. Bercak yang terbentuk kemudian dilihat menggunakan sinar UV $254 \mathrm{~nm}$ dan sinar UV $366 \mathrm{~nm}$. Hitung nilai Rf yang diperoleh dari masing-masing sampel kemudian dibandingkan dengan nilai $\mathrm{Rf}$ dari kontrol positif. Nilai Rf dihitung dengan rumus

$$
\mathrm{Rf}=\frac{\text { Jarak rambat sampel } / \text { baku }}{\text { Jarak rambat fase gerak }}
$$

Nilai Rf dinyatakan hingga angka 1,0. Nilai Rf menunjukkan pemisahan yang cukup baik berkisar antara 0,2-0,8 .

\section{HASIL DAN PEMBAHASAN \\ Hasil}

Uji organoleptis jamu memberikan hasil yang bervariasi pada sampel jamu
Tabel 1. Uji Organoleptis Sampel Jamu

\begin{tabular}{|c|c|c|c|}
\hline Sampel & Bentuk & Warna & Rasa \\
\hline A & Serbuk & $\begin{array}{c}\text { Coklat-hujau } \\
\text { muda }\end{array}$ & $\begin{array}{c}\text { Sedikit } \\
\text { pahit }\end{array}$ \\
\hline B & Serbuk & $\begin{array}{c}\text { Coklat-hijau } \\
\text { tua }\end{array}$ & $\begin{array}{l}\text { Sedikit } \\
\text { pahit }\end{array}$ \\
\hline $\mathrm{C}$ & Serbuk & Putih & $\begin{array}{c}\text { Sangat } \\
\text { pahit }\end{array}$ \\
\hline $\mathrm{D}$ & Serbuk & Coklat & Pahit \\
\hline $\mathrm{E}$ & Serbuk & $\begin{array}{c}\text { Putih } \\
\text { kecoklatan }\end{array}$ & $\begin{array}{c}\text { Sedikit } \\
\text { pahit }\end{array}$ \\
\hline $\mathrm{F}$ & Serbuk & Coklat muda & $\begin{array}{c}\text { Sedikit } \\
\text { pahit }\end{array}$ \\
\hline G & Serbuk & Coklat & $\begin{array}{l}\text { Sedikit } \\
\text { pahit }\end{array}$ \\
\hline $\mathrm{H}$ & Serbuk & Coklat muda & $\begin{array}{c}\text { Sangat } \\
\text { pahit }\end{array}$ \\
\hline
\end{tabular}

Pada tabel 2 menunjukkan hasil $\mathrm{Rf}$ baku allopurinol dan deksametason pada beberapa fase gerak. Berdasarkan hasil optimasi fase gerak dipilih fase gerak yang akan digunakan untuk analisis selanjutnya adalah Kloroform : Etil Asetat 1:4, dikarenakan pada fase gerak tersebut, baku allopurinol dan deksametason dapat teridentifikasi

\section{Tabel 2. Nilai Rf Pada Optimasi Fase Gerak}

\begin{tabular}{ccc}
\hline \multirow{2}{*}{ Fase Gerak } & \multicolumn{2}{c}{ Rf Baku } \\
\cline { 2 - 3 } & Allopurinol & Deksametason \\
\hline Kloroform : & - & 0,875 \\
$\quad \begin{array}{c}\text { Metanol } \\
\text { N-Butanol : }\end{array}$ & 0,5 & - \\
$\quad \begin{array}{c}\text { Amonium } \\
\text { Kloroform : Etil } \\
\text { asetat }(1: 2)\end{array}$ & 0,1 & 0,94 \\
$\begin{array}{c}\text { Kloroform : Etil } \\
\text { asetat }(1: 4)\end{array}$ & 0,2 & 0,75 \\
\hline
\end{tabular}

Penetapan harga Rf pada simulasi sampel dan larutan baku dapat dilihat pada tabel 3. Dari hasil tersebut dapat dilihat pada kontrol positif adanya allopurinol dan deksametason dapat terdeteksi karena dihasilkan Rf yang sama seperti pada baku. Pada Kontrol negatif bercak 
yang tampak tidak sesuai Rf baku allopurinol dan deksametason

Tabel 3. Rf pada Simulasi Sampel dan Larutan Baku Allopurinol dan Deksametason

\begin{tabular}{lccc}
\hline & Rf 1 & Rf 2 & Rf 3 \\
\hline Kontrol positif & 0,21 & 0,78 & 0,82 \\
Kontrol negatif & - & - & 0,82 \\
Baku allopurinol & 0,21 & - & - \\
Baku deksametason & - & 0,78 & - \\
\hline
\end{tabular}

Hasil analisis KLT pada 8 sampel jamu dapat dilihat pada tabel 4. Terdapat bercak selain bercak baku allopurinol dan deksametason pada sampel jamu.

Tabel 4. Rf pada filtrat sampel dan Larutan Baku Dexamethason dan Allopurinol

\begin{tabular}{lcccc}
\hline & Rf 1 & Rf 2 & Rf 3 & Ket. \\
\hline $\begin{array}{l}\text { Baku } \\
\text { Allopurinol }\end{array}$ & 0,2 & - & - & \\
$\begin{array}{l}\text { Baku } \\
\text { Deksametas } \\
\text { on }\end{array}$ & 0,87 & - & - & \\
$\begin{array}{l}\text { Sampel A } \\
\text { Sampel B }\end{array}$ & 0,42 & 0,72 & - & - \\
$\begin{array}{l}\text { Sampel C } \\
\text { Sampel D }\end{array}$ & 0,42 & 0,73 & - & - \\
Sampel E & 0,2 & 0,48 & 0,72 & $\begin{array}{c}\text { Allopuri } \\
\text { nol }\end{array}$ \\
Sampel F & 0,2 & 0,48 & 0,72 & $\begin{array}{c}\text { Allopuri } \\
\text { nol } \\
\text { Sampel G }\end{array}$ \\
Sampel H & 0,73 & - & - & - \\
\hline
\end{tabular}

\section{Pembahasan}

Gambar 1. Hasil Kromatogram baku Allopurinol, baku Deksametaso dan sampel jamu

Prosedur yang pertama kali dilakukan adalah uji organoleptis sampel jamu, yang bertujuan untuk mengetahui bentuk, warna dan rasa dari sampel jamu. Hasil uji organoleptis dapat dilihat pada tabel 1 Sampel jamu ada yang berbentuk serbuk dan ada yang berbentuk kapsul. Untuk sampel yang berbentuk kapsul, maka sampel dikeluarkan dulu dari cangkang kapsul untuk melihat bentuk, warna dan Rasa dari sampel jamu. Jika dilihat dari warna dan rasa, ada beberapa sampel jamu yang mempunyai warna dan rasa yang tidak seperti warna jamu pada umumnya, yaitu pada sampel C dan E, yang mempunyai warna putih, dan putih kecoklatan.. Warna jamu pada umumnya adalah coklat kekuningan, coklat maupun coklat kehijauan, karena berasal dari simplisia yang dihaluskan. Dari hasil pengujian rasa, ada 2 jamu yang mempunyai rasa sangat pahit, yang berbeda dari sampel jamu yang lain yaitu jamu $\mathrm{C}$ dan $\mathrm{H}$

Langkah selanjutnya adalah melakukan optimasi pada fase gerak yang akan digunakan pada metode KLT. Fase gerak yang digunakan merupakan campuran 2 atau lebih pelarut organik yang berbeda kepolarannya Beberapa fase gerak telah digunakan pada optimasi antara lain: Kloroform : metanol, 9:1, seperti 
penelitian yang dilakukan oleh Robby candra dkk, 2018, tetapi pada fase gerak tersebut, bercak allopurinol tidak terdeteksi, dan hanya bercak deksametason saja yang terdeteksi (Purnama candra, Nofita, 2018) Fase gerak lain yang digunakan adalah $\mathrm{N}$ butanol : Amonium Hidroksida, seperti penelitian maisura dkk, 2018 tetapi bercak yang muncul hanya bercak allopurinol saja (Maisura et al., 2018).

Fase gerak yang terpilih pada optimasi adalah Etil asetat dan Kloroform, hal ini berdasarkan penelitian yang dilakukan oleh Rollando 2019, melakukan analisis fenilbutazon dan parasetamol dalam Jamu. Jurnal ini digunakan karena pada beberapa jurnal yang melakukan analisis terhadap allopurinol dan deksametason, fase gerak yang digunakan tidak menghasilkan 2 bercak sesuai baku allopurinol dan deksametason (Rolando r, Erizcha D, 2019). Dilakukan 2 perbandingan yang berbeda pada komposisi fase gerak kloroform : etil asetat, yaitu pada perbandingan 1;2 dan 1;4. Pada perbandingan 1;2 baku allopurinol mempunyai harga Rf 0,1 sehingga dilakukan penambahan etil asetat menjadi 4 bagian. Rf yang terlalu kecil disebabkan karena fase gerak cenderung non polar, sehingga perlu ditambahkan fase gerak yang bersifat lebih polar yaitu Etil asetat. Fase gerak tersebut dipilih karena deksamethason dan allopurinol dapat terdeteksi bercaknya, serta memberikan harga $\mathrm{Rf}$ yang baik, Rf allopurinol sebesar 0,2 dan Rf deksametason sebesar 0,75. Metode KLT dikatakan baik jika harga Rf yang dihasilkan sebesar 0,2-0,8 (Kemendikbud, 2018).

Setelah didapatkan fase gerak yang tepat untuk KLT, langkah selanjutnya adalah mengaplikasiikan fase gerak pada simulasi sampel bersamaan dengan baku deksametason maupun allopurinol. Simulasi sampel terdiri dari kontrol negatif dan kontrol positif. Kontrol negatif terdiri dari matriks jamu sedangkan sampel positif terdiri dari matriks jamu yang telah ditambahkan dengan baku allopurinol dan deksametason. Simulasi sampel dilakukan untuk melihat apakah metode analisis yang dilakukan akurat, ditandai dengan baku allopurinol dan deksametason terdeteksi didalam sampel simulasi sampel

Metode KLT ini selanjutnya digunakan untuk mengidentifikasi ada atau tidaknya Allopurinol dan deksamethason dalam sampel jamu. Metode ini tidak sama dengan yang ada di FI ed VI, metode yang digunakan pada FI ed VI adalah metode Spektrofotometri IR (Kemenkes RI, 2020). Dari hasil KLT pada 8 sampel jamu yang diperiksa, diperoleh terdapat bercak dengan harga Rf yang bervariasi, ada yang lebih dari 1 bercak, dan ada beberapa sampel yang tidak ada bercak sama sekali. Adanya beberapa bercak pada beberapa sampel, dikarenakan memang adanya kandungan senyawa-senyawa metabolit sekunder dari sampel jamu tersebut, misalnya flavonoid, fenolik, tanin, alkaloid, steroid dsb (Julianto, 2019). Selain itu, adanya bercak yang lain, memungkinkan juga adanya Bahan Kimia Obat yang lain pada sampel jamu tersebut, misalnya natrium diklofenak, antalgin, parasetamol ataupun obat golongan analgetik yang lain (Mustarichie et al., 2017).

Terdapat 2 sampel yaitu sampel E dan F yang mengandung Allopurinol, dikarenakan mempunyai harga $\mathrm{Rf}$ yang sama dengan baku allopurinol. Berdasarkan pada penelitian yang dilakukan oleh Maisura et al., 2018 analisis kandungan BKO pada jamu di daerah Aceh dari 11 sampel jamu yang diuji ada 1 yang positif mengandung allopurinol dengan nilai Rf 0,56. Sedangkan pada pengujian terhadap deksametason tidak ada sampel yang mengandung deksametason karena tidak menghasilkan nilai Rf yang sama dengan baku deksametason. Penelitian dari Mustarichie et al., 2017 dari 7 sampel jamu di Bandung, 
terdapat 1 sampel yang positif mengandung deksametason dengan nilai $\mathrm{Rf}$ 0,66. Pada identifikasi dengan metode KLT, suatu senyawa dikatakan sama, jika mempunyai harga Rf yang sama jika dilakukan pengujian dengan metode KLT yang sama (Kemendikbud, 2018).

\section{SIMPULAN}

Metode KLT yang digunakan dapat mengidentifikasi allopurinol dan deksametason secara simultan, dan terdapat 2 sampel jamu yang mengandung allopurinol dan tidak ada sampel yang mengandung Deksametason.

\section{UCAPAN TERIMA KASIH}

Terimakasih kepada LPPM Universitas Ngudi Waluyo yang telah memberikan stimulus pendanaan dalam pelaksanaan penelitian ini

\section{DAFTAR PUSTAKA}

Asra, R., Zulharmita, \& Yuliatim, N. (2018). Determination of Dexamethasone in Unregistered Herbal Weight Gain Using HPTLC-Densitometry. Indonesian Journal of Pharmaceutical and Clinical Research, 1(2), 21-28. https://doi.org/10.32734/idjpcr.v1i2.331

Julianto, T. S. (2019). Fitokimia Tinjauan Metabolit Sekunder dan Skrining Fitokimia. In Journal of Chemical Information and Modeling (Vol. 53, Issue 9).

Kemendikbud. (2018). Buku Informasi Melaksanakan Analisa Secara Kromatografi Konvensional Mengikuti Prosedur. Dk, 53(9), 80.

Kemenkes RI. (2012). Registrasi Obat Tradisional. Peraturan Menteri Kesehatan RI No 07 Tahun 2012, 32.

Kemenkes RI. (2020). Farmakope Indonesia edisi VI. In Kementerian Kesehatan RI Republik Indonesia.
Maisura, Fauziah, \& Rinaldi. (2018). Identification of medicinal chemicals in packaging of herbal medicine sold in the aceh market by thin-layer chromatography. Borneo Journal of Pharmascientech , 2(2), 95-102.

Mustarichie, R., Ramdhani, D., \& Indriyati, W. (2017). Analysis of forbidden pharmaceutical compounds in antirheumatic jamu. Asian Journal of Pharmaceutical and Clinical Research, 10(4), 98-101. https://doi.org/10.22159/ajpcr.2017.v10i4. 16101

Pertamawati, M. H. (2015). Uji penghambatan aktivitas enzim xantin oksidase terhadap ekstrak kulit kayu secang (Caesalpinia sappan L). Karika-Jurnal Ilmiah Farmasi, 3(2), 12-17.

Purnama candra, Nofita, P. (2018). Identifikasi deksametason pada jamu Habbatussauda yang beredar di Toko obat daerah pasar tengah Bandar Lampung menggunakan metode Kromatografi Lapis Tipis. Jurnal Analis Farmasi, 3(1), 1-8.

Rolando r, Erizcha D, E. M. (2019). Penetapan kadar Fenilbutazon dan parasetamol didalam jamu Pegal Linu yang beredar di Kota Malang secara Kromatografi Lapis Tipis- densitometri. Jurnal Insan Farmasi Indonesia, 2(April), 126-138.

Saputra, S. (2015). Identifikasi Bahan Kimia Obat dalam Jamu Pegel Linu Seduh dan Kemasan yang Dijual di Pasar Bandar. Jurnal Wiyata, 2(2), 188-192.

Wulandari, L. (2011). Kromatografi Lapis Tipis. In Taman Kampus Presindo. 